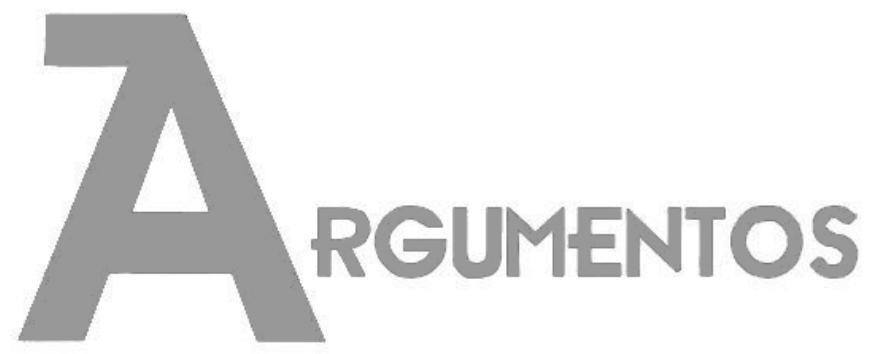

Vol. 16, n. 1, jan./jun. 2019 ISSN: 2527-2551 (online)

\title{
Performatoses do tecido social necrosado: endodissidências no eixo da necrobiopolítica e resistência à violência como uma nova epistemologia
}

\author{
Ribamar José de Oliveira Junior ${ }^{1}$ \\ Lore Fortes $^{2}$
}

Recebido em: 12/12/2018

Aprovado em: 14/03/2019

Resumo: $O$ presente artigo tem como objetivo refletir sobre a produção de subjetividades dissidentes coletivas como ferramenta de resistência à violência como uma nova epistemologia. Ao levar em consideração as contribuições de Valencia (2016) diante do capitalismo como construção biointegrada e as noções de Mbembe (2011) sobre a necropolítica, pretende-se esboçar o fenômeno da performatose como rebate a gestão da violência e a atividade predatória dos corpos, condicionados em uma perspectiva entendida por Bento (2018) de necrobiopoder. Nesse sentido, o fenômeno se debruça sobre a necessidade fagocitária de reconstituir o tecido social necrosado através do planejamento de al ianças que produzam outras formas de resistência e que desenvolvam uma agência legítima do ponto de vista geopolítico, ou seja, capazes de buscar espaços fora da asfixia gore.

Palavras-chave: Performatose; Necropolítica; Capitalismo Gore; Epistemologia; Violência.

\section{Performatos del tejido social necrosado: endodisidencias en el eje de la necrobiopolítica y resistencia a violencia como una nueva epistemología}

Resumen: El presente artículo tiene como objetivo reflexionar sobre la producción de subjetividades disidentes colectivas como herramienta de resistencia a la violencia como una nueva epistemología. Al tomar en consideración las contribuciones de Valencia (2016) ante el capitalismo como construcción biointegrada y las nociones de Mbembe (2011) sobre la necropolítica, se pretende esbozar el fenómeno de la actuación como rebate la gestión de la

\footnotetext{
${ }^{1}$ Mestrando em Ciências Sociais pela Universidade Federal do Rio Grande do Norte - Natal, Brasil. Email:<ribaeomar@gmail.com >. ORCID: https://orcid.org/0000-0002-5607-2818.

2 Professora Associada no Departamento de Ciências Sociais e no Programa de Pós-Graduação em Ciências Sociais da Universidade Federal do Rio Grande do Norte- Natal, Brasil. E-mail:< lorefortes4@gmail.com >. ORCID: https://orcid.org/0000-0003-0046-7359.
} 
violencia y la actividad predatoria de los cuerpos, condicionados en una perspectiva entendida por Bento (2018) de necrobiopoder. En este sentido, el fenómeno se centra en la necesidad fagocitaria de reconstituir el tejido social necrosado a través de la planificación de alianzas que produzcan otras formas de resistencia y que desarrollen una agencia legítima desde el punto de vista geopolítico, o sea, capaces de buscar espacios fuera de la asfixia gore.

Palabras-clave: Performatose; Necropolítica; Capitalismo Gore; Epistemología; Violencia.

\title{
Performatoses of the necrosed social tissue: endodissidences in the axis of necrobiopolitics and resistance to violence as a new epistemology
}

\begin{abstract}
This article aims to reflect on the production of collective dissident subjectivities as a tool of resistance to violence as a new epistemology. Taking into account the contributions of Valencia (2016) to capitalism as a biointegrated construction and the notions of Mbembe (2011) on necropoly, the aim is to outline the phenomenon of performance and to rebate the management of violence and the predatory activity of bodies, conditioned in a perspective understood by Bento (2018) of necrobiopoder. In this sense, the phenomenon focuses on the phagocytic need to reconstitute the necrosed social fabric through the planning of alliances that produce other forms of resistance and that develop a legitimate agency from the geopolitical point of view, that is, able to seek spaces out of suffocation gore.
\end{abstract}

Keywords: Performatose; Necropolitics; Capitalism Gore; Epistemology; Violence.

"a travestilidade eh minha divindade. minha fé" (Linn da Quebrada)

\section{Introdução}

Líquidos, sólidos e géis recobertos por um órgão que dentre extensão e peso, supera qualquer outro. A pele. Para explicar como nós havíamos nos convertido em hetero-humanos ehomo-humanos, Preciado (2009) recorre à história dos primeiros dias de revolução sexual. Em um epílogo, chamado de Terror Anal da obra de El Deseo Homossexual de Guy Hocquenghem, Preciado (2009) destaca que não há diferenças, somos todos um fragmento de pele que, respondendo às leis da gravidade, começa na boca e termina no ânus. Para situar a discussão, o filósofo contemporâneo diz que Hocquenghem havia lido Freud enquanto chupava paus nas reuniões do partido comunista francês e, como uma coisa leva a outra, havia se perguntando se o Édipo teria ânus.

Ainda que os indivíduos não nascessem homens ou mulheres, muito menos meninos e meninas, havia o medo de que toda a pele fosse um órgão sexual sem gênero. Assim, como havia o receio de que os corpos, lidos por Preciado (2009) como tubos dérmicos, buscassem formas de se controlar diante do assombro com a potencialidade 
de gozar sobre tudo. Com isso, a obra explica que os tubos dérmicos acabaram redesenhados com zonas de abjeção e de privilégio. Foi necessário então fechar o ânus, assim como foi necessário cercar as terras comuns para demarcar a propriedade privada, explana o autor. "Cerrar la ano para que la energía sexual que podría fluir a través de él se convirtiera en honorable y sana camaradería varonil, en intercambio linguístico, en comunicación, en prensa, en publicidad, en capital" 3 (PRECIADO, 2009, p. 136).

Desde então não cessaram estratégias para fechar o órgão, mas foi por meio de um método limpo dos Santos Padres, como explica o autor, que se colocou em marcha uma técnica para extirpar qualquer capacidade do ânus que não fosse de excremento. A castração do ânus se deu na exclamação de que "cierra el ano y serás proprietário, tendrás mujer, hijos, objetos, tendrás patria. A partir de ahora serás el amo de tu identidad" (PRECIADO, 2009, p. 136). Dessa forma, o ânus castrado se converteu em um mero ponto de expulsar detritos e, ao invés de expandir a função do órgão de potencialidade indefinida, nasceram, respectivamente, o corpo privado e os homens heterossexuais na cidade moderna do final do século XIX, vistos por Preciado (2009) como corpos castrados de ânus.

O ânus, no homem heterossexual, entendido apenas como orifício excretor, acaba por não ser um órgão e sim uma cicatriz da castração que segundo o pensamento do autor é o preço que o corpo paga ao regime heteross exual pelo privilégio de exercer a masculinidade. Portanto, o dano causado por uma ideologia de superioridade fez com que os homens heterossexuais se lembrassem do ânus apenas na defecação, o que os transformou em fantoches que se crêem melhores diante uma hegemonia que se sustenta na castração do ânus. "El ano castrado es el armario del heterossexual. Con la castración del ano surgió, al hundir el dólar en las tripas húmedas del infante, el pene

\footnotetext{
3 “Fechar o ânus para que a energia sexual que poderia fluir através dele se torne honrosa e saudável camaradagem varonil, em intercâmbio linguístico, em comunicação, em imprensa, em publicidade, em capital". Tradução nossa.

4 "Feche o ano e você será um proprietário, você terá uma esposa, filhos, objetos, você terá uma pátria. De agora em diante você será o mestre da sua identidade". Tradução nossa.
} 
como significante despótico. El falo aparición como mega-\$-porno-fetiche-asequible de la nueva Disney-heterossexual-land"5 (PRECIADO, 2009, p. 137).

Logo, a Cidade, o Estado e a Pátria se ergueram em torno do ânus castrado e todos os órgãos de poder administrativo passarama excluir os corpos cujos ânus permaneciam abertos, como cita Preciado (2009) sobre as mulheres duplamente perfuradas pelo ânus e pela vagina - em que seu corpo inteiro acabou transformado, pela hegemonia dos ânus castrados, em cavidade uterina capaz de abrigar cidadãos - e sobre os corpos "maricas" 6 em que o poder não pode castrar. No núcleo familiar que se tem um paianalmente-castrado e uma mãe-víscera-oca, novos tubos dérmicos vinham ao mundo para Ihes arrancarem o orifício anal. Porém, Preciado (2009) explica que o primeiro diagnóstico crítico acerca da relação entre capitalismo e heterossexualidade chegará através do dia da ira do cordeiro, época em que os corpos-não-castrados-de-ânus se rebelarão.

Ao definir a obra de Hocquenghem como um texto terrorista, Preciado (2009) retoma ao arquivo de microrrevoluções, em escala local e minúscula, para enfatizar que não havia uma linguagem exterior ao relato heterossexual, logo, o que haviam eram discursos dominantes sobre a homossexualidade, como por exemplo, os discursos médicos, psiquiátricos, psicanalíticos e midiáticos. Terrorismo aparece no epílogo em referência a Roland Barthes - Preciado (2009) traz o mesmo para destacar que o autor tinha mais dificuldades em falar da sua própria homossexualidade em público do que fazer hermenêutica - sobre obras capazes de intervir socialmente graças à violência que permite que o texto exceda e constitua sua própria inteligibilidade histórica.

O autor marca entre os anos de 1869 a 1969 o período que o Ocidente aperfeiçoa suas técnicas de morte, ao mesmo tempo, que exalta os valores da família heterossexual branca. "Los membros de la familia no tienen ano. Papá no tiene ano. Mamá no tiene ano. El niño no tiene ano. La niña, ni siquiera importa si tiene ano o no lo tiene ano ${ }^{7 \prime \prime}$ (PRECIADO, 2009, p. 139). Para o autor, em 1869, foi o momento que a linguagem

\footnotetext{
5 “O ânus castrado é o armário heteross exual. Com a castração do ânus surgiu, ao afundar o dólar nas entranhas úmidas da criança, o pênis como um significante despótico. O falo apareceu como mega -\$pornô-fetiche-acessível da nova Disney-heterossexual-land". Tradução nossa.

${ }^{6}$ Abordados pelo autor como corpos que renegam o que os outros consideram evidências an atômicas e que fazem da mutação uma estética de vida (PRECIADO, 2009).

7 “Os membros da família não tem ânus. Papai não tem ânus. Mamãe não tem ânus. O menino não tem ano. A menina, sequer importa se tem ânus ou não tem”. Tradução nossa.
} 
médico-jurídica-centro-europeia define pela primeira vez a oposição entre heterossexualidade e homossexualidade, como uma luta entre a normalidade e a patologia. Já em 1969, foi o momento em que houve a formação dos primeiros movimentos de defesa dos direitos dos homossexuais nos Estados Unidos e na Europa. Logo, o discurso heterossexual se estendeu através de uma única linguagem biopolítica sobre o corpo e a espécie. Os anormais existiam, mas não se havia um saber coletivo sobre eles mesmos.

De acordo com Preciado (2009), se passa uma época em que um conjunto de microrrevoluções, ao contrário das revoltas tradicionais, se caracterizam por serem poéticas, lúdicas, corporais e por rejeitarem o âmbito da política tradicional como primeiro es paço de luta. Em 1968, adolescentes universitários ocupam as ruas do bairro latino de Paris, as aulas deixam de ser lugar de doutrina para serem espaços de conflitos políticos. E, apesar de reunir com o pensamento marxista os trabalhadores da fábrica, os jornalistas e os meninos leitores, a revolução que se enunciava, baseada na luta de classes, era "cosa de hombres y no una simple mariconada. La izquierda define sus límites: ni maricas, ni travestis, ni drogas, sólo alcohol, su masculinidad y sus chicas" 8 (PRECIADO, 2009, p. 141).

Ao retomar a afirmação de Hocquenghem sobre a possibilidade da política revolucionária, em si mesma, gerar uma instância repressiva, Preciado (2009) afirma que as revoluções também constroem seus próprios marginais, logo, a revolução ainda não havia chegado em seu estado anal. Preciado (2009), ao recontar a versão da história que nos diz que a revolução sexual começou com os gays, destaca que a luta de fato se inicia com a lésbicas, as "maricas" afeminadas e as travestis, vistas como "las únicas que necesitaban de la revolución para sobrevivir"9 $(2009$, p. 142). A revolução anal havia de ser lenta. "Si hay que abrir el ano público, habrá que hacerlo por la vía cultural ${ }^{10 "}$ (PRECIADO, 2009, p. 144).

O período empreende o que Preciado (2009) considera o processo de fragmentação e de deslocamento que põe em questão a afirmação de um único sujeito feminista e de um único sujeito homossexual. Processo similar ao surgimento dos

\footnotetext{
8 "Coisa de homens e não de uma simples bicha. A esquerda define seus limites: nem queers, nem travestis, nem drogas, só álcool, sua masculinidade e suas garotas". Tradução nossa.

9 "As únicas que necessitavam da revolução para sobreviver". Tradução nossa.

10 "Se há de abrir o ânus ao público, haverá de fazer pela via cultural" Tradução nossa.
} 
movimentos queer diante dos movimentos homossexuais e feministas norteamericanos a partir da década de 1980. É o período em que se rebate a normalização da revolução com a proposta de coletivizar o ânus ao invés de fechá-lo. Entre 1968 e 1988 se inventam, segundo o autor, as políticas do ânus como agenciamentos coletivos frente à (bio/tanato) políticas de guerra que até então haviam sido as formas tradicionais de governo da sociedade. Preciado (2009) destaca que as micropolíticas maricas, bolleras, travestis e trans exuais que se opuseram ao modelo tradicional de política como guerra, propuseram um novo de modelo de política, principalmente em relação ao ânus, que agora aparece como um orifício antissistema, caracterizado no eixo de políticas contra biopolíticas.

Diante o regime de castração anal e por meio de micropolíticas, vistas como estratégias capazes de questionar a subjetividade na modernidade capitalista, elaboram-se pistas para o fenômeno da performatose em uma leitura das políticas anais localizadas. Procura-se considerar a partir de agenciamentos coletivos de subjetividades dissidentes, como as alianças de corpos vulneráveis podem costurar o tecido social necrosado e neutralizar os efeitos do capitalismo farmacopornográfico (PRECIADO, 2018). O objetivo deste texto é apontar um fenômeno que possa analisar os processos de castração anal e cartografar outros modos de corpos aliados em regime de precariedade (BUTLER, 2018).

Não se trata, como podemos perceber, de uma nova receita psicológica ou psicossociológica, mas de uma prática micropolítica que só tomará sentido em relação a um gigantesco rizoma de revoluções moleculares, proliferando a partir de uma multidão de devires mutantes: devir-mulher, devir-criança, devir-velho, devir-animal, planta, cosmos, devir invisível, tantas maneiras de inventar, de "maquinar" novas sensibilidades, novas inteligências da existência, uma nova doçura (GUATTARI, 1980, p. 139).

A performatose aparece como uma movimentação de subjetividades desejantes na mesma medida que aponta para a reconstrução do tecido social em termos moleculares. Consideram-se os movimentos das multidões e os devires-minoritários para traçar suturas no aspecto gore do capitalismo contemporâneo (VALENCIA, 2010) e, por meio da assembleia (BUTLER, 2018), deslocar o eixo necrobiopolítico (BENTO, 2018) que precariza de forma seletiva corpos marcados socialmente. O fenômeno procura contribuir para a maquinaria de novas sensibilidades para os agenciamentos coletivos, 
desse modo, sugere que as alianças entre os corpos dissidentes podem aparecer como uma alternativa de rebate à violência como epistemologia.

Como exemplo da performatose em contextos localizados, traz-se a performance de brincantes LGBT+ da tradição de Reisado no Cariri cearense para se pensar na forma com que devires minoritários em agenciamentos coletivos podem subverter códigos hegemônicos de gênero naturalizados na tradição, sendo esta ainda marcada pela heteronormatividade e pelo ideal de cabra macho em territórios onde a violência aparece como ferramenta de legitimidade na região do Nordeste, como explica Albuquerque Junior (1999). O caso traz dados empíricos a partir dos processos subjetivos e das políticas de subjetivação dos brincantes transviados (BENTO, 2017) e oferece uma breve reflexão sobre o que pode ser considerado o fenômeno performatose a partir da produção do corpo na cultura popular.

\section{Necrobiopoder e capitalismo gore ${ }^{11}$}

Diante do contexto histórico em que as políticas anais se organizam, pretendese, ao levar em consideração as interpretações de Valencia (2010) das consequências do capitalismo global, tecer uma relação entre a epistemologia da violência contemporânea e o necrobiopoder, como sugere Bento (2018). Ao fazer referência à reinterpretação hegemônica e global de espaços (geograficamente) fronteiriços, Valencia (2010), propõe a terminologia gore para compreender, o que se entende por "Terceiro Mundo", a partir do "preço" pago pelos países que, para a autora, é calculado sob critérios cada vez mais exigentes. Diante disso, a autora traz o cenário de Tijuana, fronteira desvinculada entre México e Estada Unidos - por vezes denominada "a última esquina" da América Latina ${ }^{12}$ - para entender os efeitos brutais da produção neoliberal que se justifica por mediação da violência mais explícita como uma ferramenta de necroempoderamento.

\footnotetext{
11 Termo que a autora toma da nomenclatura do gênero cinematográfico gore, caracterizado pelo grotesco, derramamento de sangue e vísceras. Em nota explicativa sobre o ter mo após a introdução do livro na primeira edição, Sayak Valencia (2010) ressalta que o conceito de capitalismo gore abarca os fenômenos observados de violência extrema aplicados aos corpos como ferramenta da economia mundial, sobretudo, do crime organizado, como parte importante dessa economia mundial.

12 A autora traz a expressão associada ao exemplo da cidade, "a última esquina" da América Latina, como exemplo para se pensar nos territórios fronteiriços a partir das relações de poder das redes criminais em Tijuana, México. Valencia (2010) percebe que a localização da cidade contribui para ativida de preda tória dos corpos.
} 
Nesse aspecto, o gore estaria vinculado ao derramamento de sangue e vísceras, explícito e injustificado frente ao crime organizado e aos usos predatórios dos corpos. Para Valencia (2010), o capitalismo segue para um estágio em que os corpos agora são concebidos como produtos de intercâmbio que alteram e rompem as lógicas de produção do capital, já que subvertem os termos do sistema por compreender o jogo da produção de mercadoria. O próprio corpo e a vida humana, para a autora, se tornam através de técnicas predatórias de violência extrema, a mercadoria.

É possível comparar o exemplo da análise de Tijuana com que Hilário (2016) contextualiza ao citar os fenômenos da periferia do capitalismo, em específico, aqueles que aludem a uma passagem da biopolítica para a necropolítica, sendo a esta uma política centrada na produção da morte em larga escala, como característica de um mundo em estado de exceção permanente. Tal estado, ao retomar o pensamento de Valencia (2010), se ambienta no aspecto gore. Para Hilário (2016), na época atual do capitalismo já não se trata mais de assimilação nem de expulsão de massas humanas, pois o sistema passa a se desfazer das mesmas em larga escala, ou seja, a ordem do sistema faz com que as massas sejam dispensáveis dos modos de reprodução e produção de riqueza. O autor retoma o que Marx (1988) denominou de "trabalho morto" - força de trabalho acumulada na forma maquinaria - para explicitar como sujeitos se tornam supérfluos diante do caráter vivo da produção de valor.

No caso, quando o autor cita o "trabalho morto" na produção de valor e acaba por complementar o raciocínio através do "trabalho de morte" da política, ou seja, do conceito de necropolítica de Mbembe (2011), vale retomar a definição de capitalismo gore para se entender a crise sistêmica. Valencia (2010) se refere ao capitalismo gore a partir da transvalorização de valores e práticas que tomam sua forma mais visível em territórios fronteiriços. Diante disso, ao se questionar sobre as estratégias utilizadas pelos subalternos frente às forças transnacionalizadoras do "Primeiro Mundo", Valencia (2010) enfatiza que a marginalização instiga ações para acessar essa produção capitalista por meio de formas ultraviolentas de exercer o capital.

A autora traz o pensamento do que seriam práticas gore ao citar Marx (1867) e as definições de riqueza na sociedade que estariam atreladas a acumulação de mercadoria, logo, no estágio gore do capitalismo, o processo e a destruição do corpo se convertem em si mesmos em produtos e em mercadorias acumuladas, uma vez que a morte se 
tornou o negócio mais rentável. Apesar de Hilário (2016) trazer fenômenos da periferia do capitalismo para perceber a passagem necropolítica, nos termos de Mbembe (2016), Valencia (2010) alerta que os conceitos contemporâneos são insuficientes para se analisar práticas gore, porque para tal, seria necessário um mundo em que haja espaços fora do alcance do capitalismo.

O que Valencia (2010) propõe é uma explicação para a realidade produzida pelo capitalismo gore, embasada na violência, no narcotráfico e no necropoder, mostrando algumas distopias da globalização e a sua imposição em territórios localizados como "Terceiro Mundo", para assim, perceber as práticas capitalistas que sustentam a violência sobregirada e a crueldade ultra especializada, implantadas nas formas de vida cotidiana em certas localizações geopolíticas como resultado do processo de obtenção de reconhecimento e legitimidade econômica. No pensamento da autora, o exercício da violência se sobrepõe a soberania e obedece a uma lógica derivada e concebida das estruturas e processos planejados do neoliberalismo, da globalização e da política.

Fala-se de práticas gore como aquelas transgressoras da crise sistêmica, unicamente, alerta Valencia (2010) pelo fato de que sua contundência demonstra a vulnerabilidade do corpo humano, sua mutilação e descentralização. Assim, a autora percebe que tais corpos em práticas gores tecem uma feroz crítica por não sustentar a reprodução de lógicas neoliberais em uma sociedade de hiperconsumo, promovendo ao mesmo tempo participação e engajamento no sistema. Para Valencia (2010), as práticas de violência radical se desenvolvem em lógicas predatórias a partir do advento da globalização como ferramenta de promoção do desenvolvimento social e econômico. Isto ocorre junto ao que ela denomina de especulação e espetacularização dos corpos e da violência.

Partindo disso, a autora define capitalismo gore como "uno de esos procesos de la globalizacíon, em su lado B, aquel que muestra su consecuencias sin enmascaramiento"13 (VALENCIA, 2010, p. 18). No mesmo sentido em que existem movimentos, discursos e ações de resistência que buscam fazer frente ao alcance do discurso capitalista, Valencia (2010) não limita as práticas gore a ordem discursiva. Uma vez que a autora propõe a reflexão em um espaço heteróclito que ainda não foi

\footnotetext{
13 "Como um dos processos da globalização em seu lado B, aquele que mostra suas consequências sem
} mascara-las". Tradução nossa. 
suficientemente tensionado desde as contrapropostas do capitalismo, justamente por ser considerado distópico e estar enraizado na lógica da irreflexão. Porém ela percebe a urgência de se elaborar um discurso crítico que descreva o capitalismo gore, para assim ter referências capazes de analisar e abordar os campos e suas práticas.

Se invisibilizarmos las relaciones entre la economía legal y la economía ilegal, así como el uso controlado de la violencia como elemento de necroempoderamento capitalista y enriquecimiento econômico, tambien si invisibiliza $-y$, portanto naturaliza la possibilidade de accíon contra ellos el hecho de que estos procesos regularmente inciden sobre los cuerpos de todos aquellos que forman parte del devenir minoritario, que es en donde, de uns forma e outra, toda esta violência explícita recae. (VALENCIA, 2010, p. 19) ${ }^{14}$.

Dessa forma, Valencia (2010) articula a noção de capitalismo gore, entendendo-o como a dimensão sistematicamente descontrolada e contraditória do projeto neoliberal. Dentro da identidade hiperconsumista do capitalismo, a autora pontua a criação de subjetividades capitalistas radicais, nas quais ela considera advinda de sujeitos endríagos ${ }^{15}$ e novas figuras discursivas que confrontam uma epistemologia da violência e reconfiguram o conceito de trabalho, a partir de agenciamentos perversos como pontua Kristeva (1989). Aqui, é possível tecer, ao retomar o fenômeno da periferia do capitalismo, como observa Hilário (2016), uma relação entre as massas supérfluas oriundas do "trabalho morto" e a reconfiguração da noção de trabalho na leitura do necroempoderamento, como explica Valencia (2010). Para a autora, tal agenciamento se afiança na comercialização da necropolítica do assassinato, evidenciando distopias que trazem consigo os pactos da matriz neoliberal e seus objetivos.

Frente à ordem mundial, Valencia (2010) explica que as subjetividades endríagas buscam se instalarem em si mesmas, para assim se assegurarem como sujeitos válidos e com possibilidade de pertencimento e ascensão social. O que por si possibilita a criação de novos campos oriundos de uma intervenção, vista pela autora, como feroz

\footnotetext{
14 "Se invisibilizarmos as relações entre a economia legal e economia ilegal, assim como o uso controlado da violência como el emento de necroempoderamento capitalista e enriquecimento econômico, também se invisibiliza - e, portanto, se neutraliza a possibilida de de ação contra isso - os feitos desses processos regularmente incidem sobre os corpos de todos aqueles que formam um devir minoritário, que é onde, de uma forma ou outra, toda violência explícita recai". Tradução nossa.

15 Termo adotado pela autora, oriundo da mitologia grega que se refere a um monstro lendário.
} 
descentralizada e irreparável do capitalismo. "Sujetos que contradicen las lógicas de lo aceptable y de lo normativo como consecuencia de la toma de consciencia de ser redundantes en el order económico. Haciendo frente a su situacíon y contexto por médio del necroempoderamento y las necro-práticas ${ }^{16 " ~(V A L E N C I A, ~ 2010, ~ p . ~ 20) . ~}$

Logo, o exercício da subjetividade endríaga se converte como o único processo na realidade possível, sendo legitimada pelo império da violência e os processos de economia subsumida, como por exemplo, a autora destaca sujeitos envolvidos no tráfico de drogas, armas e corpos. Ocorre assim o que Valencia (2010) denomina de inversão dos términos de vida frente ao necropoder. A vida por si, já não tem importância porque já detém um valor de mercado, se tornando objeto de intercâmbio. O que é resultado de um processo de estabilização das noções de violência desde o século $X X$, em que a autora entende como um período sinônimo de violência, posteriormente radicalizado no século XXI com a etiqueta gore devidos os avanços do neoliberalismo e o advento da globalização. Assim, a preocupação com a violência, se dá nos processos nos quais Valencia (2010) define mediante os benefícios econômicos que condicionam tanto a execução, espetacularização e a comercialização da violência pelos meios de informação.

A espetacularização da violência, para a autora, se constitui como modelo de interpretação da atualidade, assim, como elemento criador fundamental de uma epistemologia global que se estende desde as periferias aos centros do planeta e vice e versa. Logo,

esta episteme de la violencia como el conjunto de relaciones que unen muestra época con los prácticas, discursivas o no, que se orginan de esta, creando ciertas figuras epistemologicas contemporáneas que no guardan relacíon direta con lo que se había venido conociendo como los modelos adecuados de interpretacíon de la realidad; creando así uma fissura em los pactos éticos occidentales y en la aplicabilidad del discurso filosófico occidental ante las condiciones económicas, sociales, políticas y culturales del mundo actual. (VALENCIA, 2010, p. 27). ${ }^{17}$

\footnotetext{
16 “Sujeitos que contradizem do aceitável e do normativo como consequência de serem redundantes na ordem econômica. Fazendo frente a sua situação e contexto por meio de necroempoderamento e as necro-práticas". Tradução nossa.

17 "A epistemologia da violência aparece como um conjunto de relações que se unem na nossa época como as práticas, discursivas ou não, que se originam desta, criando figuras epistemológicas contemporâneas que não guardam relação direta com o que se havia conhecido como os modelos adequados de interpretação da realidade; criando assim, uma fissura nos pactos éticos ocidentais e na
} 
O capitalismo gore, para a autora, seria então, a união entre a epistemologia da violência e o capitalismo. Diante da proliferação das lógicas de globalização que legitimam identidades violentas e, em muitos casos, criminais, Valencia (2010) conta que as fronteiras, a vigilância e o controle aumentam os custos, o auge e a demanda de mercadorias gore. O resultado é o processo de passagem da biopolítica para necropolítica, em uma perspectiva gore, de transformação do Estado Nação para Mercado Nacíon, como explica Valencia (2010). Este acaba visto como uma unidade política em uma unidade econômica regida pelas leis de intercâmbio e benefício empresarial, portanto, conectada com os laços do mercado mundial.

Se no capitalismo gore as relações com os modos de produção reconfiguram o conceito de trabalho, Valencia (2010) ressalta que as práticas gore transpassam o modelo marxista de produção/consumo, pois para ela, nos encontramos imersos em uma mudança radical, principalmente ao que diz respeito ao trabalho equiparado com a grande mudança que sucedeu com a Revolução Industrial. O que a autora quer dizer com o advento das mudanças tecnológicas e eletrônicas dos últimos 25 anos, é que seria necessário repensar os conceitos marxistas de Estado, da luta de classes e da divisão social do trabalho para compreender as práticas gore, sustentadas na radicalização do capitalismo em neofeudalismo e na irrupção de um fenômeno ultraviolento. Por isso, Valencia (2010) traz o capitalismo para além de um sistema de produção, via uma matriz cultural.

A força de trabalho no capitalismo gore se substitui por meio de práticas gore, "entendidas como un ejercicio sistemático y repetido de la violencia más explícita para producir capital18" (VALENCIA, 2010, p. 51). Nessa perspectiva, seria necessário gerir a violência, e Valencia (2010) aponta este processo entre os meios autorizados de gestão da violência (Estado) e os meios desautorizados, que através da aplicabilidade violenta entre os corpos individuais, não pertencem ao sistema legítimo de gestão das ações geradoras de capital. A execução de práticas gore estaria diante do que autora denomina entre a socialização pelo consumo e as zonas sociais de exclusão. $\mathrm{O}$

aplicabilidade do discurso filosófico ocidental antes das condições econômicas, sociais, políticas e culturais do mundo atual". Tradução nossa.

18 "Entendidas como o exercício sistemático e repetitivo da violência mais explícita para produzircapital". Tradução nossa. 
biomercado, a violência decorativa e o bombardeio televisivo conduzem as práticas gore como algo lógico e legítimo no desenvolvimento da sociedade hiperconsumista e situam as mesmas em uma via eticamente distópica, como aponta Valencia (2010).

O capitalismo gore, sustentado por uma ética distópica, faz parte de um processo de produção de capital que tem suas raízes, como aponta Valencia (2010), na educação consumista da sociedade do hiperconsumo, na desregulação econômica e social e na divisão sexual do trabalho. As relações do que se entende por "Terceiro Mundo" frente as exigências da ordem econômica atual, conduzem a criação de uma ordem subjacente que faz da violência uma arma de produção globalizada. Dessa maneira, Valencia (2010) compreende o capitalismogore como uma luta intercontinental de um pós-colonialismo extremo que acaba recolonizado pelos desejos de consumo, auto afirmação e empoderamento. A autora enfatiza que a genealogia do capitalismo gore nasce e se sustenta em processos iniciados nas potências econômicas mundiais e sua s exigências no mundo contemporâneo. Como exemplo, Valencia (2010) cita a violência midiatizada dos Estados Unidos que tem como fundamento uma economia na corrida armamentista, na guerra e na gestão de outorgar, ou não, a morte dos corpos-sujeitosterritórios. Diante disso, a autora ressalta a economia como forma de violência.

O consumo gore aparece dentro das demandas sociais em uma posição geopolítica específica. Valencia (2010) discute a economia gore em uma perspectiva do capitalismo farmacopornográfico, na leitura de Preciado (2018). Recorrer a este regime que o autor considera o corpo como um dispositivo desejante, estimulado, interconectado e medicado é uma estratégia usada por Valencia (2010) para explicar os corpos mercadorias que não são capazes de prover uma autogestão de sua autonomia nas práticas gore. Valencia (2010) destaca então que o capitalismo farmacopornográfico é uma parte das ferramentas conceituais utilizadas para explicar a realidade e no seu processo de implantação estabelece uma aliança com o capitalismo gore para perceber os alcances em longo prazo do capitalismo no mundo contemporâneo.

Bento (2018) ao se questionar quem pode habitar então o Estado-Nação, entendido por Valencia (2010) como Mercado Nacíon, pontua o poder do Estado de distribuir de forma não igualitária o reconhecimento de humanidade. A vida, entre vivível e matável, segundo Bento (2018) aparece nas formas de gestão da população, em que a violência do Estado acaba legitimada pelo necropoder que teria sido 
ultrapassado pelo biopoder. Nesse sentido, a autora sugere que o necrobiopoder seria "um conjunto de técnicas de promoção da vida e da morte a partir de atributos que qualificam e distribuem os corpos em uma hierarquia que retira deles a possibilidade de reconhecimento como humano e que, portanto, devem ser eliminados e outros que devem viver" (BENTO, 2018, p. 7).

Diante dessa cultura política que se constitui na eliminação do Outro, Berenice Bento (2018) situa o medo como ferramenta do Estado em reestruturar políticas de garantias de vida e de promoções de morte. Ao tomar esse contexto de produções de subjetividades entre o capitalismo gore e o regime farmacopornográfico e nas técnicas de morte no necrobiopoder, como sugere Bento (2018), aponta-se para uma articulação do pensamento como resistência social à violência condicionada uma epistemologia. Adiante, ao levar em consideração os corpos em aliança de Butler (2018) e a reconstrução não-violenta do tecido social, esboça-se o fenômeno da performatose na leitura de subversão da subjetividade endríaga e na criação de sujeitos capazes de agenciarem e reconfigurarem a sua posição geopolítica por meio de micropolíticas coletivizadas e materializadas pelo corpo.

\section{Performatose do tecido social necrosado}

Ao retomar a castração anal e a projeção do que seria a Disney-heterossexual-land na perspectiva das políticas anais de Preciado (2009) frente ao desenvolvimento do capitalismo contemporâneo em globalização nas contribuições de Valencia (2010) é possível perceber a forma como micropolíticas agenciadas coletivamente podem rever o modelo hegemônico na criação de condições de enunciação e meios de vida. Se a história dos movimentos político-sexuais torna o gênero um indício de multidão frente à coerção do discurso violento decorativo oriundo de práticas gore, se percebe que as coletivizações desviantes permitem uma "inversão da força performativa dos discursos e de uma reapropriação das tecnologias sexo políticas de produção dos corpos dos 'anormais'”' (PRECIADO, 2011, p. 17).

Em uma análise de como o Transfeminismo pode reconstruir de forma não violenta o tecido social do México contemporâneo, Valencia Triana (2014) entende as e 
os sujeitos envolvidos no movimento como multidões queer/cuir ${ }^{19}$ que se organizam na materialização performativa das variações de gênero e sexualidades, como capazes de desenvolver agenciamentos glocais. Para a autora, a criação de políticas dissidentes de visualidades que dão visibilidade aos "movimentos trans-marikaputa-bollo-mestizxmigrante-precarix ${ }^{20 "}$ (VALENCIA TRIANA, 2014, p. 70) denunciam as consequências da violência exacerbada e vinculadas ao capitalismo gore.

O propósito é de se elaborar um cerceamento, crítico e localizado que sirva de ponto de partido para articulações entre as resistências não distópica e os temas relacionados com o uso subversivo do gênero, da linguagem, da sexualidade, da etnia/raça, da ecologia, da economia e da política. Valencia Triana (2014) aponta resistências distópicas ao mesmo tempo em que defende a ação dos movimentos em fazer da biopolítica um processo reversível frente à violência física e a opressão do sistema heteropatriarcal, hegemônico e conservador representado na atualidade pelo capitalismo gore.

O que levaria, para a autora, a uma reconstrução discursiva não abjeta com capacidade de multiplicar as possibilidades de construção de novas subjetividades. Aqui, Valencia Triana (2014) destaca as resistências distópicas na reelaboração do tecido social em contraofensiva as subjetividades endríagas do capitalismo gore. Logo, a tarefa das multidões cuir estaria em inventar outras formas de ação que reconfigurem a posição de países em desenvolvimento - ou lidos na ótica da violência decorativa como realidades que não atingem as exigências globais pelas próprias consequências do capitalismo contemporâneo - através da crítica e do arranjo geopolítico.

Valencia Triana (2014) sugere a educação para a construção de posicionamentos de gênero em uma perspectiva libertadora, autônoma e fluida, menos hierárquica e focada no direito de reivindicar a diferença. Assim como Preciado (2009) entende a educastração anal como um dispositivo específico que produz o menino - visto como um artefato biopolíticamente construído para permitir a produção e normalização do adulto - através da des-sexualização do corpo infantil e a desqualificação dos seus afetos. Logo, para Preciado (2009) o primeiro objetivo da tarefa educativa seria

\footnotetext{
19 O termo é utilizado pela autora para indicar uma tradução do queer, distante da perspectiva norteamericana de produção de enunciados, levando em consideração o contexto em que se aplica.

20 "Movimentos trans-marikaputa-bollo-mestizx-migrante-precarix, na perspectiva de Sayak (2014) seriam movimentos capazes de captar em grande alcance devi res minoritário e suas es pecificidades.
} 
privatizar o ânus em criar zonas radicalmente excluídas da economia libidinal. A repressão, nesse caso, se daria pela inserção do menino na máquina heterossexual, em firmar instituições educativas na família e fazê-lo esquecer que possui um ânus. Fechar o ânus seria desfeminilizar o corpo em um regime genitopolítico falocrático.

Para reconstruir o tecido social na perspectiva de Valencia Triana (2014), seria necessário estabelecer alianças com a masculinidade hegemônica tradicional e propor modelos desobedientes de masculinidade. Preciado (2009) complementa o pensamento da autora, quando articula que a revolução anal teria que elaborar um modelo educativo capaz de explicitar coletivamente os dispositivos de construção das minorias desviantes - devenir minoritário ${ }^{21}$, como denomina Valencia Triana (2014) - assimcomo apontar plataformas de resistência e supervivência de sujeitos abjetos na história. Ler e escrever com o ânus aberto na perspectiva de Preciado (2009) seria revisar no pensamento de Valencia Triana (2014) nos logros da reinvenção da subjetividade que o movimento cuir tem proporcionado na releitura interseccional da conduta dos coletivos LGBTT+. Valencia Triana (2014) considera reconhecer que as práticas do movimento cuir têm uma resistência pública, pacífica e eficaz, portanto sendo essenciais para a reconstrução do tecido social e para a reflexão de ponto de partida em elaborar questões sobre o problema estrutural da violência.

É nesse eixo que vale pensar no que Butler (2018) propõe com a teoria performativa em assembleia e os corpos em aliança na política das ruas. Ao entender que nem todos podem aparecer em uma forma corpórea, a autora traz notas sobre as ações corporificadas de diversos tipos para compreender como essas reuniões significam muito mais do que qualquer relato, escrito ou vocalizado, sobre o que as pessoas estão tratando. Para Butler (2018), as formas de performatividade corporificadas e plurais são componentes importantes para o entendimento sobre "o povo" e democracia.

O caráter corpóreo dos questionamentos diante das manifestações da condição precária como condição estimulante faz com que Butler (2018) entenda a produção do gênero e o direito de aparecer como as possibilidades desses corpos desempenharem o espaço público em um exercício de um direito plural e performativo. Se a economia

\footnotetext{
21 “Devir minoritário”. Tradução nossa.
} 
neoliberal traz a ideia de populações descartáveis, segundo a autora, sujeitadas à racionalidade do mercado que decide quais saúdes e vidas devem ser protegidas e quais não devem, é possível retomar as práticas gore como tentáculos das consequências mais explícitas e violentas do capitalismo.

A racionalidade liberal exige a autossuficiência como uma ideia moral, ao mesmo tempo em que as formas neoliberais de poder trabalham para destruir essa possibilidade no nível econômico, estabelecendo todos os membros da população como potencial ou realmente precários, usando até mesmo a ameaça sempre presente da precariedade para justificar a sua acentuada regulação do espaço público e sua desregulação da expansão do mercado (BUTLER, 2018, p. 20).

Portanto, a partir do momento em que alguém se prova incapaz de se adequar à norma da autossuficiência, tal sujeito se torna potencialmente descartável, segundo Butler (2018). O atravessamento da biopolítica aparece para a filós ofa com a noção de precarização. Portanto, "a fantasia do indivíduo capaz de se tornar um empreendedor de si mesmo em condições de precariedade acelerada, se não de indigência, cria a perturbadora suposição de que as pessoas podem e devem agir de maneira autônoma" (BUTLER, 2018, p. 22) aparece em diálogo com o exercício da subjetividade endríaga na perspectiva gore sob condições de vida. Se para Butler (2018), não se pode agir sem condições para agir, a percepção de que a assembleia desempenha o papel de uma forma provisória e plural de coexistência subverte a ética distópica do capitalismo gore na afirmação de uma soberania popular. Pois "os corpos reunidos 'dizem' não somos descartáveis, mesmo quando permanecem em silêncio" (BUTLER, 2018, p. 24).

Em contraponto a autossuficiência econômica como uma norma moral sob condições nas quais a mesma aparece irrealizável, os aspectos da assembleia repentina de corpos possibilitam, segundo Butler (2018), o exercício de uma performatividade plural e corpórea marcada por dependência e resistência. Chegando também a representar pela reunião de corpos em coação, a significar persistência e resistência. Diante desse contexto em que Butler (2018) aponta a abertura de caminhos por meio de redes sociais viáveis em dependência mútua no processo de elaboração de formas coletivas de se abordar à condição precária, esboça-se o significado de agir em conjunto quando as condições de ação conjunta estão em colapso gore. 
Ao tomar as considerações de Butler (2018) sobre a vulnerabilidade corporal diante da política de coligação e a posição do corpo, primeiramente e por definição, como vulnerável e inativo, se propõe o fenômeno da performatose de análise do tecido social necrosado e sua possível reconstrução não violenta por redes subjetivamente dissidentes capazes de micropoliticamente agir e gerar agenciamentos gloca is. Se "a resistência não violenta exige um corpo que aparece, age e que em sua ação busca constituir um mundo diferente daquele que o encontrou, o que significa confrontar a violência sem reproduzir em seus termos" (BUTLER, 2018, p. 204), a performatose aparece como processo desse corpo em resistência a violência como uma epistemologia nas consequências gore do capitalismo. Nesses termos, o estabelecimento de alianças em uma resistência plural e corporificada, como aponta Butler (2018) adentra a forma social necrosada, rejeita a subjetividade captada e produz endodissidências - no eixo fraturado, no pensamento de Lugones (2014) em se reproduz o pós-colonialismo extremo na paisagem necropolítica - para se reconstituir o tecido social, sendo este, capaz de se mover em transformação por meio da conexão entre si.

Ainda no que Butler (2018) postula sobre a condição precária ser apenas um fundamento da nossa igualdade potencial, a performatose assim como o modelo transfeminista de análise do tecido social mexicano proposto por Valencia Triana (2014), apresenta o desenvolvimento de agenciamentos minoritários perversos pela coletivização. O fenômeno da performatose traz em si um agente fagócito da subjetividade endríaga capaz de estabelecer redes dissidentes ou multidões desviadas por meio da endodissidência (tradução da própria dissidência) no estabelecimento de micropolíticas em uma perspectiva glocal. A atuação de redes endodissidentes nesses tecidos sociais necrosados pelo consumo gore e outras formas performativas de violência decorativa, revertem o quadro social em uma projeção de vulnerabilidade pelas performatividades corpóreas e plurais.

A atuação fagocitária da performatose do tecido social necrosado se dá na medida em que ocorre a sublimação da abjeção no sujeito individual, uma vez que a abjeção, segundo Kristeva (1988) reconhece a castraçãoe desvia das escapatórias perversas para se oferecer como não-objeto, pois a abjeção se constitui sobre o não reconhecimento de seus próximos. Nesse sentido, pode-se tomar as vinculações injuriadas de Brown (2005) no reconhecimento de auto superação como possibilidade de se dissolver em si 
mesmo, para tecer e centrar a endodissidência como possível na instalação de outra economia para além da ótica gore, ainda que provisória de meio de vida no formato da assembleia.

A micropolítica tecida pela endodissidência em paralelo ao capitalismo gore no plano macropolítico, faz com que a performatose apresente uma forma de ação em seu sentido ativo, como denomina Suely Rolnik (2016) e seja uma experiência de forças que produzem efeitos do saber-do-corpo. A performatose então se insere na cartografia asfixiada do capitalismo gore como ação desejante, resultado de um processo de criação orientado pelas multidões dissidentes, portanto, se constitui como um corpo performático plural e sensível transmissor de pulsação, segundo Suely Rolnik (2016), em que sua presença viva convoca ressonâncias nas subjetividades, inclusive na subjetividade endríaga, sendo uma política de ação do desejo capaz de ter uma relação imediata, ainda que provisória, com a necrose do tecido social.

Seguindo a micropolítica e o corpo sensível de Suely Rolnik (2016), a endodissidência se orienta pela potência do vivo e pelas ações do desejo que buscarão expandir por meio das redes dissidentes elementos fagocitários ao tecer uma micropolítica ativa. O tecido social necrosado pode se relacionar com o que Suely Rolnik (2016) chama de "anemia vital", logo, o estágio gore do capitalismo pode se localizar no que ela considera micropolítica reativa - na leitura de Valencia (2010), se identifica sobre as expectativas do "Terceiro Mundo" em suprir as demandas exigentes do capitalismo. A formação de redes dissidentes se afasta do que Rolnik (2016) estabeleceu como inconsciente colonial capitalístico, ao mesmo tempo, que se aproxima das definições de capitalismo gore. A performatose como fenômeno inventaria, pela asfixia gore, novas maneiras coletivas de existir.

Ao lado do capitalismo gore se pode considerar os processos de intoxicação e experimentação da era farmacopornográfica, como descreve Preciado (2018), as micropolíticas de gênero a partir do que o autor pontua como pós-queer. Se dentro do processo de capitalização das identidades gender-queer está evidenciado "a materialidade do corpo, à gestão da sua vulnerabilidade e à construção cultural de possibilidades de sobrevivência dentro dos processos de subjugação e organização política" (PRECIADO, 2018, p. 360), nem o trabalho nem a produção explicam o atual funcionamento da sociedade, rever a extensa rede desenvolvida pelo movimento queer 
e o Transfeminismo, considerada pelo autor, como frágeis na condução de alianças estratégicas no capitalismo global, se faz necessário para entender a perca de energia subversiva do queer.

Se anteriormente Preciado (2010) faz uma leitura da castração anal como técnica de tornar o corpo privado, na era farmacopornográfica, o ânus não é só castrado, como também codificado. $O$ farmacopoder desenha um gênero em redes de materialização biopolíticas, em que segundo o autor, se reproduz a fim de se consolidar socialmente como espetáculo, em imagem em movimento, desing in process, por vias de cibercódigos. "O tecnogênero é um biocódigo público, científico da comunidade em rede" (PRECIADO, 2018, p. 128).

Em reação ao processo de capitalização de identidades queer, Preciado (2018) aponta que uma possível emancipação farmacopornográfica de corpos subalternos só seria viável com o envolvimento, o acesso, a circulação e a interpretação dos biocódigos somatopolíticos que constroem fiç̧ões convencidas da condição natural de biomulheres e biohomens. Simultaneamente, o autor entende que o termo queer, aparece cada vez mais submetido ao processo de comercialização e decodificação diante do mercado neoliberal. Preciado (2018) ressalta estratégias que já poderiam ser consideradas "ativismo farmacopornográficos" no contexto neoliberal, ao lado de uma produção política crítica transfeminista e da produção de subjetividades dissidentes. Como resposta ao uso predatório dos corpos, seria necessário combater dispositivos geopolíticos e culturais na produção das micropolíticas de gênero. Retomar as multidões queer como eixo balizador de uma possível revolta dos ânus não castrados como reflete Preciado (2010) seria prover a habilidade de hackers de gênero, capazes de desempenharem estratégias gendercoptyleft, ou seja, traficarem os reparadores de biocódigos coptyleft farmacopornográfico.

\section{O desencantamento nas dissidências sexuais e de gênero do Reisado cartografados pela performatose}

Através da performance de brincantes LGBT+em grupos da tradição do Reisado, em Juazeiro do Norte, Ceará, é possível perceber como o fenômeno da performatose pode indicar uma releitura, próxima das estratégias gendercoptyleft (PRECIADO, 2018), 
dos códigos naturalizados de gênero na cultura popular. "A experiência dos brincantes LGBT+ pode aparecer como ferramenta de contraprodução da tradição por mesclar a vivência com a performance da dança, ou seja, evidenciar outros modos de produzir cultura popular" (OLIVEIRA JUNIOR; FORTES, 2018, p. 59).

O Reisado, segundo Barroso (2013), é um teatro nômade associado ao arranjo religioso católico que representa, em cortejo, a tradição do nascimento do menino Jesus. Por meio do jogo de espadas, cantorias e gestos dançados, os brincantes incorporam um saber adquirido pelos hábitos e pela memória e põem em cena o improviso da performance cênica. Como explica Barroso (2013), a participação das mulheres ainda é uma barreira, embora aparentemente sempre tenha exis tido, sendo a grande maioria dos brincantes, homens heterossexuais. A emergência da performance LGBT+ na tradição ocorre a partir dos artivismos das dissidências sexuais e de gênero (COLLING, 2018). O terreiro do Mestre, geralmente localizado entre o quintal e a calçada da casa, aparece como espaço educativo (OLIVEIRA JUNIOR; FORTES, 2018) e, pelo fato de possibilitar a esfera de aparição de corpos marcados socialmente pela abjeção, pode suscitar o princípio da autocobaia de Preciado (2018) e a ira do cordeiro (PRECIADO, 2009), abrindo uma reflexão para um possível terror anal nos Reisados.

De acordo com Albuquerque Junior (1999), a identidade nordestina e o gênero masculino aparecem costurados em territórios violentos, onde a violência aparece como meio de legitimidade através do exercício da virilidade. Por se tratar de uma arte nordestina, de que forma o Reisado pode ser ressignificado ao proporcionar aos corpos abjetos o estatuto de político? É nesse ponto que a performatose aparece, sobretudo, ao apontar as movimentações micropolíticas e indicar o que seriam as cartografias do desencantamento. Pois, como destaca Barroso (2013), a performance do Reisado opera entre o encantamento e o desencantamento, ou seja, na forma como o brincante, geralmente pertencente à comunidades subalternizadas, se encanta e incorpora a majestade dos personagens e se desencanta e volta a vida comum da encenação popular.

A performatose, no caso das dissidências sexuais e de gênero dentro dos grupos de Reisado, está mais próxima do corpo desencantado do que do corpo encantado, pois os processos subjetivos e as movimentações micropolíticas partem da forma com que o brincante produz a dissidência em cena. As cartografias do desencantamento apontam 
para as possibilidades do corpo e "evidenciam espaços educativos transgressores, principalmente, por alargarem as dissidências sexuais e de gênero pelo saber popular" (OLIVEIRA JUNIOR; FORTES, 2018, p. 59). Considera-se, pelos modos de vida cartografados pela performatose, que o Reisado requeira multidões transviadas encantadas e, em certa medida, possa apontar para o desenvolvimento de habilidade hackers de gênero nos códigos hegemônicos da tradição. A movimentação micropolítica parte para uma movimentação macropolítica, evidenciando os efeitos do fenômeno da performatose. De que forma o encantamento, pelo improviso cênico e pelas pulsações políticas do desejo, pode neutralizar os efeitos nocivos do regime farmacopornográfico da produção do corpo? Pensa-se na reconstrução não violenta dos esquemas regulatórios das tradições através do artivismo das alianças brincantes nas artes do Nordeste como um breve exemplo do fenômeno da performatose.

\section{Considerações finais}

Se Preciado (2009) se refere à utopia anal para enfatizar o uso coletivo do ânus, o texto apresenta por meio da performatose a continuação dos primeiros dias de revolução sexual. Ao trazer o ânus como sem sexo, sem gênero, assim como as mãos, o autor destaca que o órgão escapa da retórica da diferença sexual. Pois, "todo cuerpo (humano o animal) es primero y sobre todo ano" 22 . Portanto, o ânus seria um bioporto capaz de se inserir de uns nos outros, até porque a presença do ânus no corpo do biopenetrador dissolve a oposição, segundo o autor, entre homossexuais e heterossexuais.

O ânus, inclusive o castrado, funciona como ponto zero de "comenzar una operacíon de desterritorialización del cuerpo heterosexual" 23 (PRECIADO, 2009, p. 171). Também, como destaca o autor, o ânus é um ponto de fuga pelo qual o capital escapa. Assim, se pode dizer que o ânus é ponto de partida para se pensar as castrações e asfixias do capitalismo gore. Ao trazer o órgão como abjeto na política, se propõe por meio das políticas anais estratégias de não se castrar o ânus na implementação de uma economia global cada vez mais violenta e explícita, mediada pelo hiperconsumismo.

\footnotetext{
22 "Todo corpo (humano ou animal) é primeiro e, sobretudo, ânus". Tradução nossa.

23 "Começar uma operação de desterritorialização do corpo heteross exual". Tradução nossa.
} 
O fenômeno da performatose como resistência a violência como epistemologia, reflete sobre o processo de produção de subjetividades dissidentes coletivas como ferramenta situada na passagem da biopolítica para necropolítica. Foca então, na necessidade fagocitária de se reconstituir o tecido social necrosado através do planejamento de alianças que produzam outras formas de resistência e que desenvolvam uma agência que se legitime de lugares diferentes de poder, aparecendo também na reconstrução discursiva não abjeta da inscrição de novas subjetividades.

A performatose indica uma movimentação da própria dissidência, pois se faz necessário uma releitura da subjetividade apropriada pela ótica gore do sistema em crise. O estabelecimento de redes endodissidentes lidas como vetores do "saber-docorpo", nos moldes de Rolnik (2016) sensível a precariedade e a vulnerabilidade na perspectiva butleriana, desafia os espaços geopoliticamente situados e reativos. A capacidade fagocitária do fenômeno sugere a reconstrução do tecido social de forma não violência, como descreve Valencia (2010), e aponta para agenciados glocais resistentes a lógica que procura fundar identidades a serem captadas e não posicionamentos e enunciados reversíveis da realidade gore.

Por exemplo, quando Natalha Claudinei Silva Nascimento ${ }^{24}$, professora de matemática transexual dentro de uma sala no Fórum de Justiça de Brasília-DF, ministra aulas de questões de gênero à equipe da pastelaria Viçosa - que a agrediu e humilhou, aponta-se um possível horizonte da performatose na medida em que isso mostra a reconstrução não-violenta do tecido social. Entender que Natalha, ao lecionar desloca, pela via da educação, enunciados e relações de poder, é compreender que o discurso da professora detém uma política de subjetivação e estabelece um elo com possíveis micropolíticas por agenciamentos dissidentes. Natalha subverte a abjeção e hackeia, na perspectiva de Preciado (2018), modelos hegemônicos e estruturais de violência. A performatose acaba entendida como um processo para outros modos de vida, o caminho para subverter os dispositivos que produzem o sujeito farmacopornográfico através da aliança e aponta o rompimento com o eixo que baliza e conduz a violência decorativa gore. O fenômeno aparece como processo estratégico provisório para a

\footnotetext{
24 Ver mais em: <https://www.bbc.com/portuguese/brasil-45347986>
} 
consolidação de outras lógicas de sistema, como traz Renata Carvalho ${ }^{25}$, um rumo para a possibilidade de estratégias, pedagogias e devires travestis, um possível Traviarcado.

\section{Bibliografia}

BENTO, Berenice. Necrobiopoder: Quem pode habitar o Estado-nação?. Cad. Pagu [online]. N. 53, e185305, p. 1-18, 2018.

BUTLER, Judith. Corpos em aliança e a política das ruas: notas para uma teoria performativa da assembleia / Judith Butler; tradução Fernanda Siqueira Miguens; revisão técnica Carla Rodrigues. - 10 edição - Rio de Janeiro: Civilização Brasileira, 2018.

BROWN, Wendy. Vinculaciones injuriadas. Araucaria. Revista Iberoamericana de Filosofía, Política y Humanidades, v. 7, n. 14, p. 59-85, 2005.

COLONNA, Noemia. A professora transexual que trocou indenização de $R \$ 20$ mil pela chance de dar aula a seus agressores. Disponível em: <https://www.bbc.com/portuguese/brasil-45347986?ocid=socialflow facebook>. Acesso em 31 de agosto de 2018.

GUATTARI, Félix. Revolução molecular: pulsações políticas do desejo. São Paulo: Editora Brasiliense, 1980.

HILÁRIO, Leomir Cardoso. Da Biopolítica à Necropolítica: Variações Foucaultianas na Periferia do Capitalismo. Sapere Aude v. 7, n. 12, 194-210, janeiro-junho, 2016.

KRISTEVA, Julia. Poderes de la perversión: ensayo sobre Louis-Ferdinand Céline. Siglo XXI, 1989.

LUDEMIR, Chico. "Quem quer me matar está em nome de Deus". 25 de junho de 2018. Disponível em: <https://revistacontinente.com.br/secoes/entrevista/rque mquer-me-matar-esta-em-nome-de-deusr>. Acesso em 9 de abril de 2019.

LUGONES, María. Rumo a um feminismo descolonial. Estudos Feministas, v. 22, n. 3 p. 935-952, setembro-dezembro, 2014.

MARX, Karl. O capital: crítica da economia política. Livro I: o processo de produção do capital. São Paulo: Abril Cultural, 1988.

\footnotetext{
25 Ver mais em: <https://revistacontinente.com.br/secoes/entrevista/rquem-quer-me-matar-esta-emnome-de-deusr $>$
} 
MBEMBE, Joseph Achille. Necropolítica: seguido de" Sobre el gobierno privado indirecto". Melusina, 2011.

OLIVEIRA JUNIOR, Ribamar José de; FORTES, Lore. O tempo de exceção do riso no Reisado: a cartografia da performance de brincantes transviados e o terreiro do mestre como espaço educativo. Diversidade e Educação, v. 6, n. 2, p. 53-61, 2018.

PRECIADO, Beatriz. Terror Anal: apuntes sobre los primeros días de la revolución sexual. In HOCQUENGHEM, Guy. El deseo homosexual. Santa Cruz de Tenerife / España: Editorial Melusina, 2009. Beatriz. Multidões queer: notas para uma política dos' anormais'. (Universidade de Paris VIII). Revista de Estudos Feministas. Trad: Cleiton Zóia Mündhow, Viviane Teixeira Silveira (org. 2003). Estudos Feministas, Florianópolis, v. 19, n. 1, p. 11 20, janeiro-abril, 2011.

- Paul B. Testo Junkie: Sexo, drogas e biopolítica na era farmacopornográfica. N-1 edições, 2018.

ROLNIK, Suely. A hora da micropolítica. Série Pandemia. São Paulo: n-1 edições, 2016.

SAYAK, Valencia. Capitalismo gore. Barcelona: Editorial Melusina, 2010.

VALENCIA TRIANA, Sayak. Teoría transfeminista para el análisis de la violencia machista y la reconstrucción no-violenta del tejido social en el México contemporáneo. Universitas humanística, n. 78, p. 66-88, janeiro de 2014. 